\title{
Failed Clearance of Aneuploid Embryonic Neural Progenitor Cells Leads to Excess Aneuploidy in the Atm-Deficient But Not the Trp53-Deficient Adult Cerebral Cortex
}

\author{
Michael J. McConnell, ${ }^{1,2,4}$ Dhruv Kaushal, ${ }^{3,4}$ Amy H. Yang, ${ }^{2,4}$ Marcy A. Kingsbury, ${ }^{4}$ Stevens K. Rehen, ${ }^{4}$ Kai Treuner, ${ }^{1}$ \\ Robert Helton, ${ }^{1}$ Emily G. Annas, ${ }^{1}$ Jerold Chun, ${ }^{2,3,4}$ and Carrolee Barlow ${ }^{1,3}$ \\ ${ }^{1}$ The Salk Institute for Biological Studies, Laboratory of Genetics, La Jolla, California 92037, Graduate Programs in ${ }^{2}$ Biomedical Sciences and \\ ${ }^{3}$ Neurosciences, and ${ }^{4}$ Department of Pharmacology, School of Medicine, University of California, San Diego, La Jolla, California 92093
}

\begin{abstract}
Aneuploid neurons populate the normal adult brain, but the cause and the consequence of chromosome abnormalities in the CNS are poorly defined. In the adult cerebral cortex of three genetic mutants, one of which is a mouse model of the human neurodegenerative disease ataxia-telangiectasia (A-T), we observed divergent levels of sex chromosome (XY) aneuploidy. Although both A-T mutated $(\mathrm{Atm})$ - and transformation related protein 53 (Trp53)-dependent mechanisms are thought to clear newly postmitotic neurons with chromosome abnormalities, we found a $38 \%$ increase in the prevalence of XY aneuploidy in the adult $\mathrm{Atm}^{-1-}$ cerebral cortex and a dramatic $78 \%$ decrease in $\operatorname{Trp} 53^{-1-}$ mutant mice. A similar $43 \%$ decrease in adult XY aneuploidy was observed in DNA repair-deficient $\mathrm{Xrcc5}^{-1-}$ mutants. Additional investigation found an elevated incidence of aneuploid embryonic neural progenitor cells (NPCs) in all three mutants, but elevated apoptosis, a likely fate of embryonic NPCs with severe chromosome abnormalities, was observed only in $\mathrm{Xrcc5} 5^{-1-}$ mutants. These data lend increasing support to the hypothesis that hereditary mutations such as ATM-deficiency, which render abnormal cells resistant to developmental clearance, can lead to late-manifesting human neurological disorders.
\end{abstract}

Key words: aneuploidy; neurodegeneration; development; apoptosis; ataxia-telangiectasia; DNA damage signaling

\section{Introduction}

The overproduction and clearance of embryonic neural progenitor cells (NPCs) and newly postmitotic neurons are essential aspects of cerebral cortical neurogenesis (Blaschke et al., 1996; Kuida et al., 1996; Thomaidou et al., 1997; Pompeiano et al., 2000; Li et al., 2003). Recent findings suggest that some aneuploid NPCs are cleared whereas others survive and give rise to genetic mosaicism in the mature cerebral cortex (Rehen et al., 2001; Osada et al., 2002; Kaushal et al., 2003; Yang et al., 2003). Other studies have implicated altered genetic mosaicism, in the form of chromosome abnormalities and chromosome instability, in the pathogenesis of human neurodegenerative (Potter, 1991; Li et al., 1997; Geller and Potter, 1999; Rolig and McKinnon, 2000) and

Received June 9, 2004; revised July 20, 2004; accepted July 25, 2004.

This work was supported by the National Institute of Neurological Disorders and Stroke, V Foundation, and Searle Scholars Program (C.B.); the National Institute of Mental Health, Helen L. Dorris Child and Adolescent Neural and Psychiatric Disorder Institute, and an unrestricted gift from Merck Research Laboratories (J.C.); predoctoral support from a National Institute of General Medical Sciences Pharmacology training grant (M.J.M. and A.H.Y.) and the National Science Foundation (D.K.); postdoctoral support from the PEW Latin American Fellows (S.K.R.); and a Neuroplasticity of Aging Training grant (M.A.K.). We are grateful to Dr. H. L. Borges for critical reading of this manuscript and to F. He and the University of California, San Diego Biostatistics and Informatics Consulting Laboratory for assistance with statistical tests. We thank Dr. F. H. Gage for helpful advice and Dr. H. L. Borges, M. Hemming G. Kennedy, M. Fontanoz, and D. Mitchell for technical assistance.

Correspondence should be addressed to Dr. Carrolee Barlow, The Salk Institute for Biological Studies, Laboratory of Genetics, La Jolla, CA 92037. E-mail: barlow@salk.edu.

D. Kaushal's present address: Howard Hughes Medical Institute, The Children's Hospital, Boston, MA 02446.

M. J. McConnell, A. H. Yang, M. A. Kingbury, S. K. Rehen, and J. Chun's current address: Department of Molecular Biology and Helen L. Dorris Institute, The Scripps Research Institute, La Jolla, CA 92037.

DOI:10.1523/JNEUROSCI.2263-04.2004

Copyright $\odot 2004$ Society for Neuroscience $\quad$ 0270-6474/04/248090-07\$15.00/0 neuropsychiatric disease (Burd et al., 1985; DeLisi et al., 1994; Lewis et al., 1995; Konstantareas and Homatidis, 1999; Yurov et al., 2001; Oliveira et al., 2003). Methodological considerations, such as the difficulty of identifying aneuploid human neurons in vivo and of obtaining high-quality human brain tissue, limit the direct study of neural aneuploidy and human disease; however, studies in ataxia-telangiectasia (A-T) mutated $(\mathrm{Atm})^{-1-}$ mice suggest that late-manifesting neurodegeneration in A-T patients may reflect the generation and failed clearance of NPCs and newly postmitotic neurons with chromosome abnormalities (Herzog et al., 1998; Rolig and McKinnon, 2000; Allen et al., 2001). To explore a link between neural aneuploidy and A-T, we determined the incidence and character of neural aneuploidy in $\mathrm{Atm}^{-1-}$ mutant mice relative to wild-type (WT) cohorts.

A complex array of cerebral cortical phenotypes have been reported for mice lacking Atm or transformation related protein 53 (Trp53), which encodes the tumor suppressor protein $\mathrm{p} 53$, and genes that encode nonhomologous end-joining (NHEJ) DNA repair proteins such as $\mathrm{Xrcc5}$, known also as Ku80/86 (Chun and Schatz, 1999a,b). Three NHEJ mutants, $\mathrm{Xrcc}^{-1-}, \mathrm{Ku}^{-1-}$, or Prkdc ${ }^{-1-}$, have comparatively mild neurodevelopmental phenotypes (Gu et al., 2000; Chechlacz et al., 2001) that are worsened when Atm is also absent, leading to early embryonic lethality (Sekiguchi et al., 2001). Yet, two other NHEJ mutants, DNA ligase $4\left(\mathrm{Lig4}^{-1-}\right)$ or $\mathrm{Xrcc}^{-1-}$, present with massive neurodevelopmental apoptosis that is partially rescued by the loss of either Atm or Trp53 (Frank et al., 2000; Gao et al., 2000; Lee et al., 2000; Sekiguchi et al., 2001; Lee and McKinnon, 2002). One explanation for these divergent findings is that the various DNA repair 
deficits differentially sensitize embryonic NPCs and newly postmitotic neurons to oxidative DNA damage and resultant apoptosis (Karanjawala et al., 2002a,b). It follows then that loss of cell cycle control and related apoptotic signaling, attributable to Atm or Trp53 deficiency, complements lethal DNA repair deficits and permits the survival of $\mathrm{Lig} 4^{-1-}$ and $\mathrm{Xrcc} 4^{-1-}$ neural cells with chromosome abnormalities. This reasoning led us to hypothesize that neural aneuploidy would be similarly affected in both $\mathrm{Atm}^{-1-}$ and Trp53 $3^{-1-}$ mutants. To better elucidate the individual aspects of Atm signaling [i.e., combined DNA repair, cell cycle control, and apoptotic signaling (Kastan et al., 2000; Shiloh, 2003)] during neurodevelopment, we compared neural aneuploidy in $\mathrm{Atm}^{-1-}$ mutants with neural aneuploidy in $\mathrm{Xrcc5} 5^{-1-}$ [i.e., predominantly DNA repair deficits (Lieber et al., 2003)] and Trp53 $3^{-1-}$ [i.e., predominantly cell cycle control and apoptotic deficits (Vogelstein et al., 2000)] mutants.

\section{Materials and Methods}

Animals. All animal procedures were performed according to protocols approved by the Salk Institute for Biological Studies or the University of California, San Diego animal care and use committee. A. Nussenzweig (National Cancer Institute, Bethesda, MD) kindly provided $X r c c 5^{-/-}$ mice (C57BL/6J background) (Nussenzweig et al., 1996). Atm $^{-1-}$ mice (129S6/SvEvTac background) were generated as described previously (Barlow et al., 1996). Age-matched, male 129S3/SvImj and 129S3/SvImjTrp53 mice were purchased from Jackson Laboratories (Bar Harbor, ME). Trp53 $3^{-1-}$ embryos (129S6/SvEvTac background) were a generous gift from J. Wang (University of California, San Diego, La Jolla, CA). All animals were derived from heterozygote breedings within each mutant background with controls derived from littermates of the same background. Females were monitored daily for the presence of a copulation plug. This day was deemed embryonic day 0.5 (E0.5) and embryos were collected at the time of gestation indicated. Only tumor-free animals were analyzed. All analyses were performed in a blinded manner.

Spectral karyotyping. Cerebral cortical hemispheres were dissected from individual embryos between E12.5 and E14.5 and maintained at $37^{\circ} \mathrm{C}$ in $0.5 \mathrm{ml}$ of OptiMEM media containing $0.02 \mathrm{M}$ glucose, $0.055 \mathrm{M}$ 2-mercaptoethanol, $1 \times$ penicillin-streptomycin-glutamine solution, $100 \mathrm{ng} / \mathrm{ml} \mathrm{Colcemid,} \mathrm{and} 50 \mathrm{ng} / \mathrm{ml}$ basic fibroblast growth factor-2 (all from Invitrogen, Carlsbad, CA) for $3 \mathrm{hr}$. Hemispheres were dissociated by gentle trituration, and cells were collected by centrifugation at $350 \times$ $g$ for $5 \mathrm{~min}$. The cell pellet was resuspended by drop-wise addition of 0.75 $\mathrm{ml}$ of hypotonic solution $(0.075 \mathrm{M} \mathrm{KCl})$ while vortexing slowly. After 15 min at room temperature (RT), three drops of fixative (three parts $100 \%$ methanol:one part glacial acetic acid) were added and cells were collected by centrifugation. The supernatant was removed to a residual volume of $0.05 \mathrm{ml}$, and $0.75 \mathrm{ml}$ of RT fixative was added drop-wise while vortexing. After overnight incubation at $4^{\circ} \mathrm{C}$, the cells were washed twice in RT fixative, as described above. Cells were stored at $4^{\circ} \mathrm{C}$ until spread preparation. Adult NPCs were prepared as described by Allen et al. (2001).

Prometaphase-metaphase chromosome spreads were prepared as described previously (Henegariu et al., 2001; Rehen et al., 2001). Fixed cells from appropriate genotypes were selected and blinded until analysis was complete. Results were pooled from at least three individual embryos. Spectral karyotyping (SKY) (Liyanage et al., 1996) was performed on slides that were aged for 3-7 d at RT and then hybridized with mouse SKY paint [Applied Spectral Imaging (ASI), Carlsbad, CA] at $37^{\circ} \mathrm{C}$ for $24 \mathrm{hr}$. Excess probe was removed and hapten-labeled nucleotides were detected using the concentrated antibody detection kit (ASI) and following manufacturer's instructions. Karyotypes were determined from $100 \times$ micrographs captured using a Zeiss Axioplan 2 (Zeiss, Thornwood, NY), Spectracube interferometer and charge-coupled device camera (ASI), and Spectral Imaging and SKYview software (ASI).

XY fluorescence in situ hybridization. Cerebral cortices were dissected from at least three age-matched WT and mutant adult (8-14 weeks of age) male mice. Nuclei were isolated by detergent lysis, affixed to glass slides, and hybridized with whole chromosome paints (ASI), as described previously (Rehen et al., 2001; Kaushal et al., 2003; Yang et al., 2003). Samples (200-400 nuclei) from each animal were scored for the presence or absence of sex chromosomes and pooled for statistical analysis. No significant difference was detected in the proportions of aneuploid nuclei in the C57BL/6J and 129S6/SvEvTac strains, so we pooled data from these WT nuclei and performed statistical analysis on $\mathrm{Atm}^{-1-}$ and $\mathrm{Xrcc5}^{-1-}$ mutant strains versus pooled WT cohorts.

Histochemistry. Embryos or adult brains were embedded in Tissue-Tek OCT (Sakura Finetek, Torrance, CA), frozen using dry ice, and stored at $-80^{\circ} \mathrm{C}$. Before fixation, $10 \mu \mathrm{m}$ sections were sliced using a cryostat. Matched sections from each genotype were mounted on each slide. "In situ end-labeling plus" (ISEL +) was performed as described previously (Blaschke et al., 1996; Chun and Blaschke, 1997). Sections were counterstained with 4',6-diamidino-2-phenylindole (DAPI). At least three animals from each genotype were analyzed, and representative micrographs are presented. Images were acquired using a Zeiss Axiocam and Zeiss imaging software and prepared using Photoshop 6.0 (Adobe Photo Systems, San Jose, CA).

Data analysis. Fisher's exact test was performed using R software (Free Software Foundation's GNU project, Boston, MA). Other statistical analyses were performed, and graphs were prepared using Excel $2000(\mathrm{Mi}-$ crosoft, Redmond, WA) and Photoshop 6.0. $\chi^{2}$ analysis used $2 \times 2$ contingency tables (euploid vs aneuploid) to calculate predicted values from observed data. Student's $t$ test was performed on parametric data assuming a two-tailed distribution and homoscedastic variance.

\section{Results}

The prevalence of adult XY aneuploidy is increased in $\mathrm{Atm}^{-1-}$ mutants and decreased in $\mathrm{Xrcc5}^{-1-}$ and $\operatorname{Trp53} 3^{-/-}$mutants

To study the consequences of impaired DNA repair and/or cell cycle and apoptotic signaling on the prevalence of aneuploidy in the adult cerebral cortex, XY fluorescence in situ hybridization

\section{Sex Chromosome Karyotype}

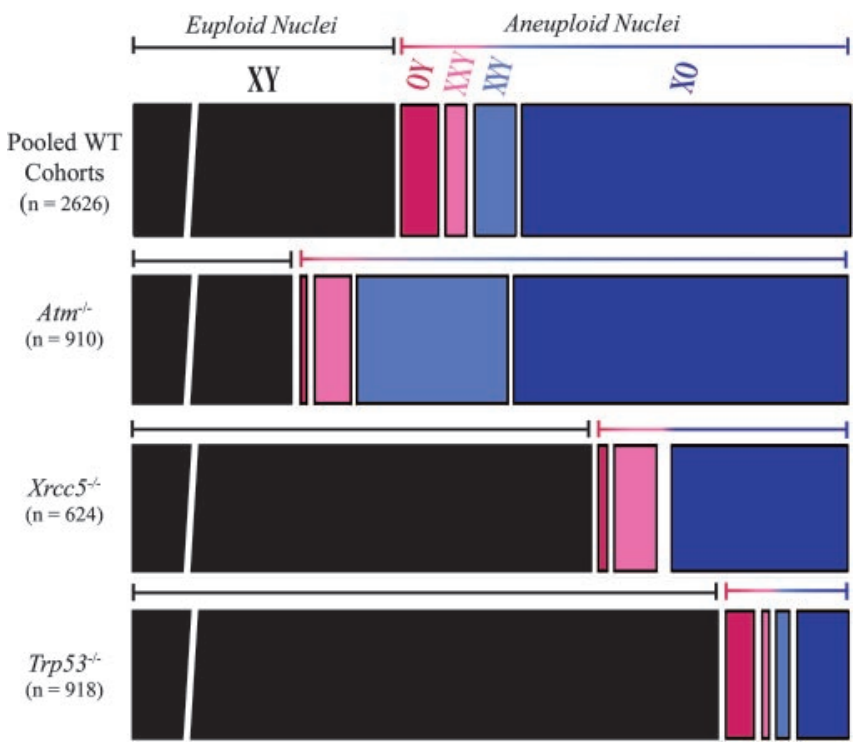

Figure 1. Adult $\mathrm{XY}$ aneuploidy is elevated in the $\mathrm{Atm}^{-I-}$ cerebral cortex but diminished in the Xrcc5 ${ }^{-1-}$ and $T r p 53^{-1-}$ cerebral cortex. A mosaic display (Friendly, 1994) compares the proportion of cells with specific patterns of adult XY neural aneuploidy ( $O Y, X X Y, X Y Y, X 0)$ in WT (top box) and mutant mice (genotypes indicated). For each category, the total number of nuclei analyzed $(n)$ is indicated in parentheses. The width of each segment indicates the relative proportion of nuclei in each category (numerically represented in Table 1). Black bars (representing euploid nuclei) are broken to indicate that the relative widths are truncated. Colored bars (pink and blue) indicate aneuploid nuclei. Dark pink indicates $X$ chromosome loss (OY), and $X$ chromosome gain is indicated by light pink (XXY). Light blue indicates $Y$ chromosome gain $(X Y Y)$, and dark blue indicates $Y$ chromosome loss ( $X 0)$. 
(XY FISH) (Rehen et al., 2001; Kaushal et al., 2003) was performed on nuclei isolated from the cerebral cortex of adult male mice (subsequently referred to as nuclei) and mutant cohorts with germ-line null mutations in Atm, Xrcc5, and Trp53. XY FISH uses X chromosome and Y chromosome whole chromosome paints, conjugated with distinct fluorophores, to determine the rates of gain and loss for each member of the chromosome pair and estimate the overall prevalence of aneuploidy in interphase nuclei. This method allowed us to determine the following: (1) the overall prevalence of adult XY aneuploidy, measured by the percentage of nuclei that had gained (XXY or XYY) or lost (OY or $\mathrm{XO}$ ) a sex chromosome and (2) the character of adult $X Y$ aneuploidy, measured by the relative proportions of $\mathrm{XY}$ versus $\mathrm{OY}$ versus $\mathrm{XXY}$ versus $\mathrm{XYY}$ versus $\mathrm{XO}$ nuclei. We found an increased prevalence of aneuploid nuclei in $\mathrm{Atm}^{-1-}$ mutants (WT, 51 of 902 nuclei, $5.7 \%$ aneuploidy vs mutant, 70 of 910 nuclei, $7.7 \%$ aneuploidy) and a decreased prevalence in both $X r c c 5^{-1-}$ (WT, 49 of 814 nuclei, 6\% aneuploidy vs mutant, 21 of 624 nuclei, $3.4 \%$ aneuploidy) and $\operatorname{Trp} 53^{-/-}$(WT, 64 of $910 \mathrm{nu}-$ clei, $7 \%$ aneuploidy vs mutant, 14 of 918 nuclei, $1.5 \%$ aneuploidy) mutants (Fig. 1, Table 1). In addition, statistical analysis confirmed a significant difference in the character of XY aneuploidy that was observed in each mutant relative to WT cohorts (Fig. 1, Table 1).

The relationship between adult XY aneuploidy and adult XX aneuploidy or autosomal aneuploidy is not yet known. Although sex chromosome aneuploidy (DeLisi et al., 1994; Samango-Sprouse, 2001) and $X$ chromosome mosaicism (Gleeson et al., 2000; Samango-Sprouse, 2001) have been specifically linked to neurological disease, the mechanism through which XY mosaicism affects normal or pathological brain function is not clear. Altered levels of XY aneuploidy as a reflection of overall aneuploidy can, however, direct further study of the neurodevelopmental parameters that shape overall aneuploidy. It is likely that many of the aneuploid adult nuclei we observed were isolated from the progeny of aneuploid embryonic NPCs (Davis and Temple, 1994; Price and Willshaw, 2000; Qian et al., 2000). Therefore, we next asked whether an altered prevalence of aneuploid embryonic NPCs could account for altered adult $\mathrm{XY}$ aneuploidy in these mutants.

\section{Embryonic NPC aneuploidy is elevated when the DNA} damage response is compromised

If the prevalence of adult XY aneuploidy is a direct consequence of the prevalence of embryonic NPC aneuploidy, then dimin-
Table 1. Sex chromosome karyotypes in the adult cerebral cortex

\begin{tabular}{|c|c|c|c|c|c|c|}
\hline \multirow[b]{2}{*}{ Mutant } & \multicolumn{5}{|c|}{ Number of nuclei observed (fold change relative to $\mathrm{WT}^{a}$ ) } & \multirow{2}{*}{$\begin{array}{l}\text { Prevalence of aneuploid nuclei } \\
\text { (fold change relative to } \mathrm{WT}^{a} \text { ) }\end{array}$} \\
\hline & $X Y$ & OY & $X X Y$ & $X Y Y$ & $x_{0}$ & \\
\hline $\mathrm{Atm}^{-/-^{b}}$ & 840 & $1(0.4)$ & $5(2.7)$ & $20(2.2)$ & $44(1.1)$ & $7.7 \%(1.3)$ \\
\hline $\operatorname{xrcc5} 5^{-1-c}$ & 603 & $1(1.3)$ & $4(1.3)$ & $0\left(^{e}\right)$ & $16(0.4)$ & $3.4 \%(0.5)$ \\
\hline $\operatorname{Trp} 53^{-1-^{d}}$ & 904 & $4(0.3)$ & $2(0.3)$ & $1(0.4)$ & $7(0.1)$ & $1.5 \%(0.2)$ \\
\hline
\end{tabular}

${ }^{a}$ Fold change is calculated by dividing the percentage of aneuploid nuclei observed in mutant mice by the percentage of aneuploid nuclei observed in WT cohorts. A fold change $<1$ indicates a relative increase.

${ }^{b}$ Fisher's exact test versus WT cohorts (see Materials and Methods), $p<0.05$.

'Fisher's exact test versus WT cohorts, $p<0.001$.

${ }^{d}$ Fisher's exact test versus WT cohorts, $p<0.0001$.

${ }^{e}$ Fold change cannot be calculated for zero observations relative to one observation.
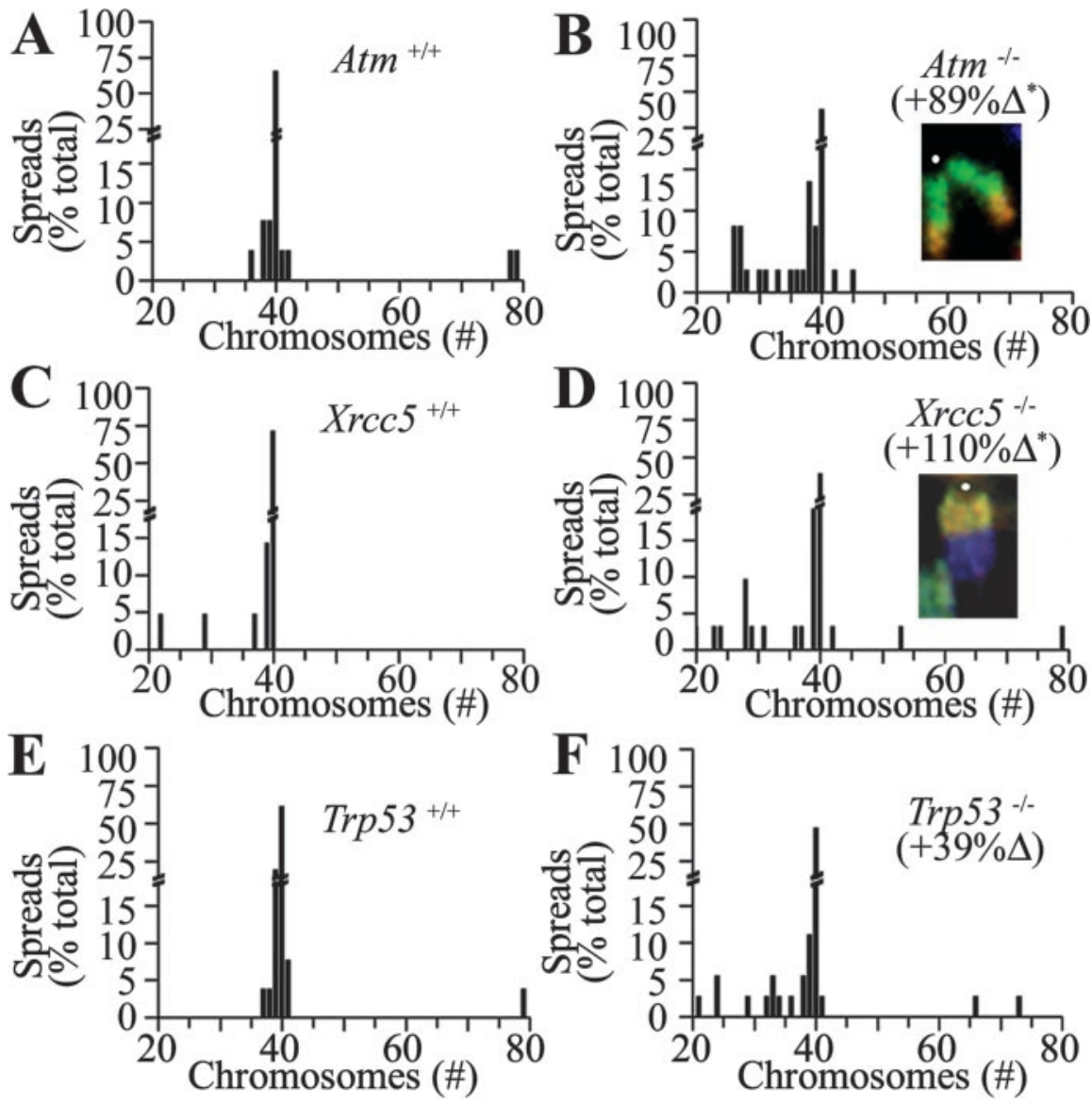

Figure 2. Embryonic NPC aneuploidy is increased in all mutants. The number of chromosomes observed by SKY in prometaphase-metaphase chromosome spreads is indicated on the $x$ axis; the euploid chromosome number in a laboratory mouse is 40 . The percentage of prometaphase-metaphase chromosome spreads containing an indicated number of chromosomes is plotted on the y axis. $A, B$, The prevalence of aneuploid embryonic NPCs increased from $35 \%$ in $A t m{ }^{+/+} \mathrm{NPCs}(A)$ to $66 \%$ in $\mathrm{Atm}^{-1-} \mathrm{NPC}$ $(B)\left({ }^{*} p<0.05, \chi^{2}\right) . B$, Inset, $A t(3 ; 14)$ translocation was observed in an aneuploid $A t m^{-1-}$ embryonic NPC. C, D, The prevalence of aneuploid embryonic NPCs increased from $29 \%$ in $X r c c 5^{+/+} \mathrm{NPCs}(C)$ to $61 \%$ in $X r c c 5^{-1-} \mathrm{NPCs}(D)\left(^{*} p<0.03, \chi^{2}\right)$. D, Inset, A $t(5 ; 13)$ translocation was observed in an aneuploid $X_{r c c 5}{ }^{-1-}$ adult NPC. E, $F$, The prevalence of aneuploid embryonic NPCs increased from $38 \%$ in $\operatorname{Trp} 53^{+/+} \mathrm{NPCS}(E)$ to $53 \%$ in Trp53 $3^{-/-} \mathrm{NPCS}(F)$. White dots mark the centromere in inset micrographs.

ished embryonic NPC aneuploidy should correlate with diminished adult XY aneuploidy and vice versa. Because embryonic NPCs are mitotic, we used SKY (Liyanage et al., 1996; Rehen et al., 2001) to determine the prevalence of embryonic NPC aneuploidy in $\mathrm{Atm}^{-1-}, \mathrm{Xrcc5}^{-1-}$, and $\operatorname{Trp} 53^{-1-}$ embryos relative to WT cohorts. We observed a statistically significant increase in the percentage of aneuploid embryonic NPCs in $\mathrm{Atm}^{-1-}(+89 \% \Delta)$ (Fig. $2 A$ vs $B$ ) and $X r c c 5^{-1-}(+110 \% \Delta)$ (Fig. $2 C$ vs $D$ ) embryos. A similar trend toward increased embryonic NPC aneuploidy 

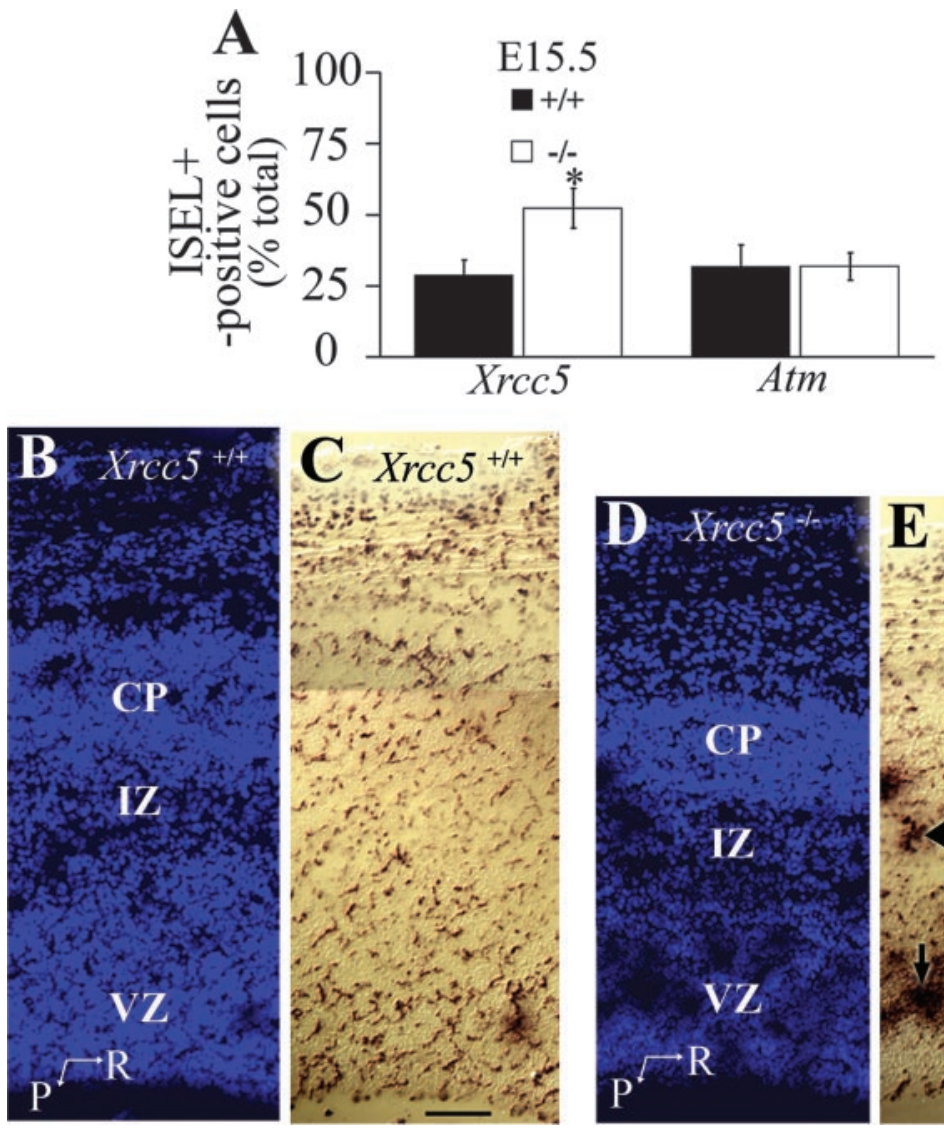

Figure 3. Developmental cell death is elevated in the ventricular zone of $X r c c 5^{-1-[\text { supi] }}$ but not $A t m^{-1-}$ embryos. ISEL + identifies developmental cell death among embryonic NPCs in the cerebral cortical VZ. A, Quantification of ISEL + staining in E15.5 embryos. The $x$ axis indicates the strain of WT $(\square)$ and mutant $(\square)$ embryos. The percentage of labeled cells (Xrcc5 ${ }^{+/+}, 28.8 \pm$ $5.4 \%$ vs Xrcc5 ${ }^{-1-}, 52.2 \pm 7 \% ;$ Atm $^{+/+}, 31.7 \pm 7.6 \%$ vs Atm $^{-1-}, 31.7 \pm 4.8 \%$ ) is plotted on the yaxis. Error bars indicate the SEM. ${ }^{*} p<0.05$; Student's $t$ test. $B, D$, In low-magnification $(10 \times)$ micrographs of DAPI-stained sections from $X r c c 5^{+/+}(B)$ and $X_{r c c 5^{-I-}}(D)$ embryonic cortex; the VZ, intermediate zone (IZ), and cortical plate (CP) are distinguishable as cell-dense (VZ, $(P)$ and cell-sparse (IZ) regions. The lateral ventricle (V), as well as rostral (R) and posterior (P) directions, are noted for orientation. $C$, $E$, Nomarski images of ISEL +-stained sections from $B$ and $D$. Dying cells are present (brown precipitate) in all anatomical regions of WT mice ( $C$ and observed more frequently and in clusters in the VZ (small arrows) and IZ (large arrow) of $\operatorname{Xrcc}^{-1-}$ mice $(F)$. Scale bars, $100 \mu \mathrm{m}$.

was observed in $\operatorname{Trp} 53^{-1-}$ embryos $(+39 \% \Delta)$ (Fig. $2 E$ vs $\left.F\right)$. In all cases, most aneuploid NPCs were hypoploid. These data show that in the absence of Atm there is a clear correlation between elevated embryonic NPC aneuploidy and elevated XY aneuploidy in the adult cerebral cortex. Paradoxically, in $X r c c 5^{-1-}$ and Trp53 $3^{-1-}$ mutants, embryonic and adult aneuploidy were inversely correlated.

\section{Chromosome translocations in vivo are detected in the absence of Atm}

One possible explanation for these divergent findings is that the character of aberrant embryonic NPCs (chromosome gain and loss vs chromosome translocations) in some way influences their ability to survive and populate the adult CNS. Previous studies have reported that Atm or Xrcc5 deficiency results in dividing cells that accumulate gains or losses of whole chromosomes as well as chromosomal translocations (Difilippantonio et al., 2000; Allen et al., 2001; Hande et al., 2001; Sekiguchi et al., 2001); however, in $\operatorname{Trp5} 3^{-1-}$ dividing cell populations, chromosome translocations are rarely detected (Ferguson et al., 2000a,b; Sekiguchi et al., 2001). In addition to chromosome gains and losses, the use of SKY allowed us to analyze acutely dissociated

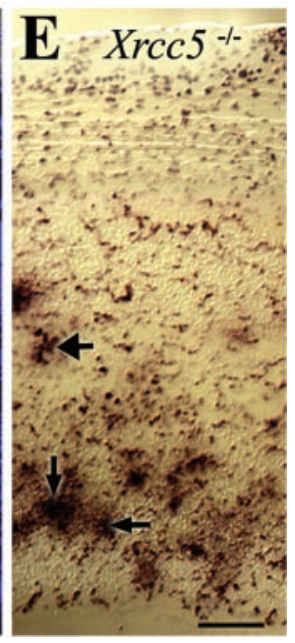

embryonic NPCs for the presence or absence of chromosome translocations. Among acutely dissociated $\mathrm{Atm}^{-1-}$ embryonic NPCs, chromosome translocations were observed in 2 of 23 aneuploid Atm $^{-1-}$ embryonic NPCs (Fig. $2 B$, inset), but none were observed in 14 euploid embryonic NPCs. Although chromosome translocations have been observed in $X r c c 5^{-1-}$ and other NHEJ-deficient mouse embryonic fibroblasts (MEFs) (Difilippantonio et al., 2000; Ferguson et al., $2000 \mathrm{a}, \mathrm{b})$, we were unable to identify any chromosome translocations in either euploid or aneuploid ( $n=31$ total studied) $\mathrm{Xrcc5}^{-/-}$embryonic NPCs. Importantly, consistent with analysis of $\operatorname{Trp} 53^{-1-}$ MEFs and lymphocytes (Ferguson et al., 2000a,b; Sekiguchi et al., 2001), no chromosome translocations were observed among $36 \operatorname{Trp} 53^{-1-}$ embryonic NPCs. In a previous study, we observed chromosome translocations and aneuploidy in cultured $\mathrm{Atm}^{-1-}$ adult NPCs (Allen et al., 2001); therefore, we prepared and studied similarly cultured $X r c c 5^{-/-}$adult NPCs in which we also observed chromosome translocations (Fig. 2D, inset) and aneuploidy (mutant, 91\% vs WT, 46\%; data not shown). The observation of chromosome translocations in cultured, aneuploid $X r c c 5^{-1-}$ adult NPCs, but not in acutely isolated, aneuploid $X r c c 5^{-1-} \mathrm{em}$ bryonic NPCs, suggests that although either $\mathrm{Atm}^{-1-}$ or $\mathrm{Xrcc5}^{-1-}$ cells with translocations can survive and proliferate in vitro, aneuploid $\mathrm{Xrcc5}^{-1-}$, but not Atm $^{-1-}$, embryonic NPCs harboring chromosome translocations are cleared rapidly in vivo.

Despite similar levels of embryonic NPC aneuploidy, only Xrcc5 deficiency leads to elevated embryonic NPC apoptosis Recently, studies using terminal deoxynucleotidyl transferasemediated nick end labeling (TUNEL) to detect apoptotic cells demonstrated that mice deficient in $\mathrm{Xrcc5}^{-/-}$have higher levels of apoptosis among newly postmitotic neurons (Gu et al., 2000; Karanjawala et al., 2002a). In contrast, in $\operatorname{Tr} p 53^{-1-}$ mutants, no evidence of elevated neurodevelopmental apoptosis was reported using TUNEL (Frenkel et al., 1999; Klocke et al., 2002) or using a more sensitive assay (M. Pompeiano, S. Rehen, and J. Chun, unpublished observations), termed in situ end-labeling plus (Blaschke et al., 1996; Chun and Blaschke, 1997). We used ISEL + to definitively establish whether there were elevated or reduced levels of apoptosis in $\mathrm{Xrcc5}^{-1-}$ and $\mathrm{Atm}^{-1-}$ embryonic NPCs. An $81 \%$ increase in the number of ISEL+-labeled cells was detected in the ventricular zone (VZ) of E15.5 $X r c c 5^{-1-}$ (Fig. 3) embryos. In contrast, Atm $^{-1-}$ embryos showed staining similar to WT controls (Fig. 3A). Thus, although embryonic NPC aneuploidy is elevated in all genotypes, only $\mathrm{Xrcc5} 5^{-/-}$mutants show clear evidence of resultant apoptosis during cortical development. Taken together, these data suggest that the decreased adult XY aneuploidy in 
$X r c c 5^{-/-}$mutants reflects a culling of embryonic NPCs with deleterious chromosome abnormalities. In contrast, increased adult XY aneuploidy in Atm ${ }^{-1-}$ mutants is likely the consequence of both an elevated occurrence and a failure to eliminate karyotypically aberrant embryonic NPCs.

\section{Discussion}

The hypothesis that karyotypically aberrant neural cells are involved in the pathology of A-T is based on SKY analysis of cultured $\mathrm{Atm}^{-1-}$ adult NPCs (Allen et al., 2001) and inferred from the failed clearance of presumably abnormal neural cells after irradiation (Herzog et al., 1998). The main goal of this study was to directly examine the karyotypes of acutely isolated cells from the developing and mature $\mathrm{Atm}^{-1-} \mathrm{CNS}$. In $\mathrm{Atm}^{-1-}$ mutant mice, we found an elevated incidence of aneuploidy and chromosome translocations among embryonic NPCs (Fig. 2), no evidence for the neurodevelopmental clearance of additional aneuploid embryonic NPCs (Fig. 3), and elevated XY aneuploidy in the adult cerebral cortex (Fig. 1, Table 1). These observations demonstrate that Atm deficiency promotes both the ontogenesis and survival of aneuploid embryonic NPCs and their progeny. Comparison of Atm $^{-1-}$ and $\mathrm{Xrcc5}^{-1-}$ neurodevelopment suggests that DNA repair functions to prevent translocations and limit aneuploidy in a subset of embryonic NPCs, and that Atm-dependent signaling pathways play a significant role in the clearance of severely aberrant embryonic NPCs.

What determines the mosaic composition of the mature cerebral cortex? Although our data (Blaschke et al., 1996; Pompeiano et al., 2000; Rehen et al., 2001) and that of others (Kuida et al., 1996; Thomaidou et al., 1997; Li et al., 2003) demonstrate that apoptotic mechanisms clear many aneuploid embryonic NPCs during development, the basis for this decision is unknown. XY FISH measures aneuploidy for only 1 of the 20 mouse chromosome pairs; therefore, it is only an estimate of the overall prevalence and character (i.e., the mosaic composition) of neural aneuploidy. However, three observations from this analysis suggest that selection based on genetic factors shapes the mosaic composition of the adult cerebral cortex. First, there is a propensity for $\mathrm{Y}$ chromosome aneuploidy (Fig. 1, OY $+\mathrm{XXY}<\mathrm{XYY}+\mathrm{XO}$ in all cases) as opposed to $\mathrm{X}$ chromosome aneuploidy in the male cerebral cortex. This observation is consistent with a minimal genetic impact of Y chromosome aneuploidy on selection during neurodevelopment. Other mechanisms, such as loss of heterozygousity (Kaushal et al., 2003) or ploidy-dependent gene expression (Galitski et al., 1999) among autosomes, may dictate the prevalence of $\mathrm{X}$ chromosome aneuploidy. Second, a conserved bias for chromosome loss is observed in both the developing (Fig. 2) (Rehen et al., 2001) and mature cerebral cortex (Fig. 1, XO + OY $>\mathrm{XXY}+\mathrm{XYY}$ in all cases). This may indicate that selection during neurodevelopment favors chromosome loss rather than chromosome gain. A third observation that extends this notion is that many additional hyperploid nuclei were observed only in $\mathrm{Atm}^{-1-}$ mutants (Table 1, $\mathrm{Atm}^{-1-} \mathrm{XXY}, 2.7$-fold change and $\mathrm{Atm}^{-1-} \mathrm{XYY}, 2.2$-fold change). This observation is consistent with the hypothesis that normal selection-clearance mechanisms select against hyperploid cells and that these normal mechanisms are compromised during $\mathrm{Atm}^{-1-}$ neurodevelopment.

Why is adult XY aneuploidy diminished in $\operatorname{Trp} 53^{-1-}$ mice when, unlike $X r c c 5^{-1-}$ mutants, there is no evidence for elevated clearance of embryonic NPCs during $\operatorname{Tr} 553^{-1-}$ development? Because p53 and p53 family proteins affect neuronal survival (Miller et al., 2000), one possibility is that $\operatorname{Trp53}$ is more important for the survival of aneuploid than of euploid NPCs and/or neurons. In this scenario, net developmental cell death would be constant, whereas adult XY aneuploidy is diminished (Table 1, Fig. 1). Additional possibilities include late manifesting apoptosis of aneuploid Trp53 $53^{-1-}$ neurons (Amson et al., 2000) or an altered contribution of the VZ relative to other germinal zones [e.g., the ganglionic eminence (Anderson et al., 2002)] in the Trp53-1- cerebral cortex. Regardless of the underlying events leading to diminished $\operatorname{Trp} 53^{-1-}$ adult $\mathrm{XY}$ aneuploidy, the additional aneuploidy, chromosome translocations, and resultant cell death observed in $X r c c 5^{-1-}$, but not $\operatorname{Trp5} 3^{-1-}$, mutants make it clear that impaired DNA repair and impaired cell cycle control diminish adult XY aneuploidy via distinct mechanisms. The divergent levels of adult XY aneuploidy that we observed in the $\mathrm{Atm}^{-1-}$ and $\operatorname{Trp53} 3^{-1-}$ cerebral cortex demonstrates that these proteins have distinct roles in cell cycle control and apoptotic signaling during cerebral cortical neurogenesis and suggests that novel neurodevelopmental signaling may distinguish Atm-dependent rescue of Lig4 and Xrcc4-deficient neurogenesis from Trp53-dependent rescue of these mutants.

This study has significant clinical implications for the treatment of hereditary neurological diseases. In the CNS of A-T patients, altered genetic mosaicism may manifest as neurodegeneration later in life. Moreover, related consequences of altered genetic mosaicism, not necessarily limited to specific genes, could underlie the purported links between chromosome abnormalities and Alzheimer's disease (Potter, 1991; Geller and Potter, 1999), schizophrenia (DeLisi et al., 1994; Yurov et al., 2001), and/or autism (Burd et al., 1985; Konstantareas and Homatidis, 1999; Oliveira et al., 2003). If the mosaic composition of the cerebral cortex is altered during human development, as our study demonstrates for DNA damage-signaling mutant mice, then it may be challenging to use only pharmacological means to treat such patients. In this setting, stem cell-based replacement or augmentation may be a more efficacious therapy for afflicted individuals.

\section{References}

Allen DM, van Praag H, Ray J, Weaver Z, Winrow CJ, Carter TA, Braquet R, Harrington E, Ried T, Brown KD, Gage FH, Barlow C (2001) Ataxia telangiectasia mutated is essential during adult neurogenesis. Genes Dev 15:554-566.

Amson R, Lassalle JM, Halley H, Prieur S, Lethrosne F, Roperch JP, Israeli D, Gendron MC, Duyckaerts C, Checler F, Dausset J, Cohen D, Oren M, Telerman A (2000) Behavioral alterations associated with apoptosis and down-regulation of presenilin 1 in the brains of p53-deficient mice. Proc Natl Acad Sci USA 97:5346-5350.

Anderson SA, Kaznowski CE, Horn C, Rubenstein JL, McConnell SK (2002) Distinct origins of neocortical projection neurons and interneurons in vivo. Cereb Cortex 12:702-709.

Barlow C, Hirotsune S, Paylor R, Liyanage M, Eckhaus M, Collins F, Shiloh Y, Crawley JN, Ried T, Tagle D, Wynshaw-Boris A (1996) Atm-deficient mice: a paradigm of ataxia telangiectasia. Cell 86:159-171.

Blaschke AJ, Staley K, Chun J (1996) Widespread programmed cell death in proliferative and postmitotic regions of the fetal cerebral cortex. Development 122:1165-1174. 
Burd L, Kerbeshinn J, Fisher W, Martsolf JT (1985) A case of autism and mosaic of trisomy 8. J Autism Dev Disord 15:351-352.

Chechlacz M, Vemuri MC, Naegele JR (2001) Role of DNA-dependent protein kinase in neuronal survival. J Neurochem 78:141-154.

Chun J, Blaschke AJ (1997) Identification of neural programmed cell death through the detection of DNA fragmentation in situ and by PCR. In: Current protocols in neuroscience (Crawley JN, Gerfen CR, Rogawski MA, Sibley DR, Skolnick P, Wray S, eds), pp 3.8.1-3.8.19. New York: Wiley.

Chun J, Schatz DG (1999a) Rearranging views on neurogenesis: neuronal death in the absence of DNA end-joining proteins. Neuron 22:7-10.

Chun J, Schatz DG (1999b) Developmental neurobiology: alternative ends for a familiar story? Curr Biol 9:R251-R253.

Davis AA, Temple S (1994) A self-renewing multipotential stem cell in embryonic rat cerebral cortex. Nature 372:263-266.

DeLisi LE, Friedrich U, Wahlstrom J, Boccio-Smith A, Forsman A, Eklund K, Crow TJ (1994) Schizophrenia and sex chromosome anomalies. Schizophr Bull 20:495-505.

Difilippantonio MJ, Zhu J, Chen HT, Meffre E, Nussenzweig MC, Max EE, Ried T, Nussenzweig A (2000) DNA repair protein Ku80 suppresses chromosomal aberrations and malignant transformation. Nature 404:510-514

Ferguson DO, Sekiguchi JM, Chang S, Frank KM, Gao Y, DePinho RA, Alt FW (2000a) The nonhomologous end-joining pathway of DNA repair is required for genomic stability and the suppression of translocations. Proc Natl Acad Sci USA 97:6630-6633.

Ferguson DO, Sekiguchi JM, Frank KM, Gao Y, Sharpless NE, Gu Y, Manis J, DePinho RA, Alt FW (2000b) The interplay between nonhomologous end-joining and cell cycle checkpoint factors in development, genomic stability, and tumorigenesis. Cold Spring Harb Symp Quant Biol 65:395-403.

Frank KM, Sharpless NE, Gao Y, Sekiguchi JM, Ferguson DO, Zhu C, Manis JP, Horner J, DePinho RA, Alt FW (2000) DNA ligase IV deficiency in mice leads to defective neurogenesis and embryonic lethality via the p53 pathway. Mol Cell 5:993-1002.

Frenkel J, Sherman D, Fein A, Schwartz D, Almog N, Kapon A, Goldfinger N, Rotter V (1999) Accentuated apoptosis in normally developing p53 knockout mouse embryos following genotoxic stress. Oncogene 18:2901-2907.

Friendly M (1994) Mosaic display for multiway contingency tables. J Am Stat Assoc 89:190-200.

Galitski T, Saldanha AJ, Styles CA, Lander ES, Fink GR (1999) Ploidy regulation of gene expression. Science 285:251-254.

Gao Y, Ferguson DO, Xie W, Manis JP, Sekiguchi J, Frank KM, Chaudhuri J, Horner J, DePinho RA, Alt FW (2000) Interplay of p53 and DNA-repair protein XRCC4 in tumorigenesis, genomic stability and development. Nature 404:897-900.

Geller LN, Potter H (1999) Chromosome missegregation and trisomy 21 mosaicism in Alzheimer's disease. Neurobiol Dis 6:167-179.

Gleeson JG, Minnerath S, Kuzniecky RI, Dobyns WB, Young ID, Ross ME, Walsh CA (2000) Somatic and germline mosaic mutations in the doublecortin gene are associated with variable phenotypes. Am J Hum Genet 67:574-581.

Gu Y, Sekiguchi J, Gao Y, Dikkes P, Frank K, Ferguson D, Hasty P, Chun J, Alt FW (2000) Defective embryonic neurogenesis in Ku-deficient but not DNA-dependent protein kinase catalytic subunit-deficient mice. Proc Natl Acad Sci USA 97:2668-2673.

Hande MP, Balajee AS, Tchirkov A, Wynshaw-Boris A, Lansdorp PM (2001) Extra-chromosomal telomeric DNA in cells from Atm $(-/-)$ mice and patients with ataxia-telangiectasia. Hum Mol Genet 10:519-528.

Henegariu O, Heerema NA, Lowe Wright L, Bray-Ward P, Ward DC, Vance GH (2001) Improvements in cytogenetic slide preparation: controlled chromosome spreading, chemical aging and gradual denaturing. Cytometry 43:101-109.

Herzog KH, Chong MJ, Kapsetaki M, Morgan JI, McKinnon PJ (1998) Requirement for Atm in ionizing radiation-induced cell death in the developing central nervous system. Science 280:1089-1091.

Karanjawala ZE, Murphy N, Hinton DR, Hsieh CL, Lieber MR (2002a) Oxygen metabolism causes chromosome breaks and is associated with the neuronal apoptosis observed in DNA double-strand break repair mutants. Curr Biol 12:397-402.
Karanjawala ZE, Adachi N, Irvine RA, Oh EK, Shibata D, Schwarz K, Hsieh CL, Lieber MR (2002b) The embryonic lethality in DNA ligase IVdeficient mice is rescued by deletion of Ku: implications for unifying the heterogeneous phenotypes of NHEJ mutants. DNA Repair (Amst) 1:1017-1026.

Kastan MB, Lim DS, Kim ST, Xu B, Canman C (2000) Multiple signaling pathways involving ATM. Cold Spring Harb Symp Quant Biol 65:521-526.

Kaushal D, Contos JJ, Treuner K, Yang AH, Kingsbury MA, Rehen SK, McConnell MJ, Okabe M, Barlow C, Chun J (2003) Alteration of gene expression by chromosome loss in the postnatal mouse brain. J Neurosci 23:5599-5606.

Klocke BJ, Latham CB, D'Sa C, Roth KA (2002) p53 deficiency fails to prevent increased programmed cell death in the $\mathrm{Bcl}-\mathrm{X}(\mathrm{L})$-deficient nervous system. Cell Death Differ 9:1063-1068.

Konstantareas MM, Homatidis S (1999) Chromosomal abnormalities in a series of children with autistic disorder. J Autism Dev Disord 29:275-285.

Kuida K, Zheng TS, Na S, Kuan C, Yang D, Karasuyama H, Rakic P, Flavell RA (1996) Decreased apoptosis in the brain and premature lethality in CPP32-deficient mice. Nature 384:368-372.

Lee Y, McKinnon PJ (2002) DNA ligase IV suppresses medulloblastoma formation. Cancer Res 62:6395-6399.

Lee Y, Barnes DE, Lindahl T, McKinnon PJ (2000) Defective neurogenesis resulting from DNA ligase IV deficiency requires Atm. Genes Dev 14:2576-2580.

Lewis KE, Lubetsky MJ, Wenger SL, Steele MW (1995) Chromosomal abnormalities in a psychiatric population. Am J Med Genet 60:53-54.

Li J, Xu M, Zhou H, Ma J, Potter H (1997) Alzheimer presenilins in the nuclear membrane, interphase kinetochores, and centrosomes suggest a role in chromosome segregation. Cell 90:917-927.

Li MO, Sarkisian MR, Mehal WZ, Rakic P, Flavell RA (2003) Phosphatidylserine receptor is required for clearance of apoptotic cells. Science 302:1560-1563.

Lieber MR, Ma Y, Pannicke U, Schwarz K (2003) Mechanism and regulation of human non-homologous DNA end-joining. Nat Rev Mol Cell Biol 4:712-720.

Liyanage M, Coleman A, du Manoir S, Veldman T, McCormack S, Dickson RB, Barlow C, Wynshaw-Boris A, Janz S, Wienberg J, Ferguson-Smith MA, Schrock E, Ried T (1996) Multicolour spectral karyotyping of mouse chromosomes. Nat Genet 14:312-315.

Miller FD, Pozniak CD, Walsh GS (2000) Neuronal life and death: an essential role for the p53 family. Cell Death Differ 7:880-888.

Nussenzweig A, Chen C, da Costa Soares V, Sanchez M, Sokol K, Nussenzweig MC, Li GC (1996) Requirement for Ku80 in growth and immunoglobulin $V(D) J$ recombination. Nature 382:551-555.

Oliveira G, Matoso E, Vicente A, Ribeiro P, Marques C, Ataide A, Miguel T, Saraiva J, Carreira I (2003) Partial tetrasomy of chromosome 3q and mosaicism in a child with autism. J Autism Dev Disord 33:177-185.

Osada T, Kusakabe H, Akutsu H, Yagi T, Yanagimachi R (2002) Adult murine neurons: their chromatin and chromosome changes and failure to support embryonic development as revealed by nuclear transfer. Cytogenet Genome Res 97:7-12.

Pompeiano M, Blaschke AJ, Flavell RA, Srinivasan A, Chun J (2000) Decreased apoptosis in proliferative and postmitotic regions of the Caspase 3-deficient embryonic central nervous system. J Comp Neurol 423:1-12.

Potter H (1991) Review and hypothesis: Alzheimer disease and Down syndrome-chromosome 21 nondisjunction may underlie both disorders. Am J Hum Genet 48:1192-1200.

Price DJ, Willshaw DJ (2000) Mechanisms of cortical development (Huang CL-H, Dolphin AC, Green R, Spyer KM, eds), p 22. New York: Oxford UP.

Qian X, Shen Q, Goderie SK, He W, Capela A, Davis AA, Temple S (2000) Timing of CNS cell generation: a programmed sequence of neuron and glial cell production from isolated murine cortical stem cells. Neuron 28:69-80.

Rehen SK, McConnell MJ, Kaushal D, Kingsbury MA, Yang AH, Chun J (2001) Chromosomal variation in neurons of the developing and 
adult mammalian nervous system. Proc Natl Acad Sci USA 98:13361-13366.

Rolig RL, McKinnon PJ (2000) Linking DNA damage and neurodegeneration. Trends Neurosci 23:417-424.

Samango-Sprouse C (2001) Mental development in polysomy X Klinefelter syndrome (47, XXY; 48, XXXY): effects of incomplete X inactivation. Semin Reprod Med 19:193-202.

Sekiguchi J, Ferguson DO, Chen HT, Yang EM, Earle J, Frank K, Whitlow S, Gu Y, Xu Y, Nussenzweig A, Alt FW (2001) Genetic interactions between ATM and the nonhomologous end-joining factors in genomic stability and development. Proc Natl Acad Sci USA 98:3243-3248.

Shiloh Y (2003) ATM and related protein kinases: safeguarding genome integrity. Nat Rev Cancer 3:155-168.
Thomaidou D, Mione MC, Cavanagh JF, Parnavelas JG (1997) Apoptosis and its relation to the cell cycle in the developing cerebral cortex. J Neurosci 17:1075-1085.

Vogelstein B, Lane D, Levine AJ (2000) Surfing the p53 network. Nature 408:307-310.

Yang AH, Kaushal D, Rehen SK, Kreidt K, Kingsbury MA, McConnell MJ, Chun J (2003) Chromosome segregation defects contribute to aneuploidy in normal neural progenitor cells. J Neurosci 23:10454-10460.

Yurov YB, Vostrikov VM, Vorsanova SG, Monakhov VV, Iourov IY (2001) Multicolor fluorescent in situ hybridization on post-mortem brain in schizophrenia as an approach for identification of low-level chromosomal aneuploidy in neuropsychiatric diseases. Brain Dev 23 [Suppl 1]:S186-S190. 